\title{
Los desalojos colectivos en Brasil: una crítica al protagonismo judicial
}

\author{
Collective evictions in Brazil: a criticism of the prominent role of the Judicial
}

\author{
Jorge Rubem Folena de Oliveira \\ Sociedad Brasileña de Geografía e Instituto de los Abogados Brasileños, Brasil, \\ jorgefolena@yahoo.com.br
}

Recibido: 6 de enero, 2015 Aceptado: 24 de noviembre, 2015

\begin{abstract}
Resumen: En este trabajo se hace una crítica al supuesto "protagonismo judicial", a partir de la posición adoptada por el Poder Judicial en los casos de desalojo colectivo, por medio de decisiones expedidas por los jueces, en donde miles de personas son echadas a la calle, repentinamente, en las comunidades brasileñas pobres.
\end{abstract}

El objetivo de la investigación fue constatar la crueldad practicada, por medio de decisiones judiciales, en los casos de desalojos colectivos; una práctica en que los intereses individuales de los propietarios ha prevalecido sobre el derecho social de la vivienda, en las grandes ciudades de Brasil.

El método de análisis de caso se utilizó, de los años 2012 y 2014, en dos situaciones de grandes repercusiones sociales en Brasil. La primera se refiere a las reintegraciones de pose del edificio de la Telemar, en la Ciudad de Río de Janeiro y la segunda, en la comunidad de Pinheirinho, en São José dos Campos, en el estado de São Paulo.

Palabras clave: Desalojo colectivo, decisiones judiciales, derecho a la vivienda, comunidades, Brasil.

Abstract: This paper criticizes the so-called "prominent judicial role", based on the position by the Judicial Branch in cases of collective eviction through judge rulings, in which thousands of people in the poor communities of Brazil are thrown to the streets without further notice.

The objective of this research project was to verify acts of cruelty through rulings in cases of collective evictions, where the individual interests of the owners have prevailed over the right to social housing in the big cities of Brazil.

Case analysis was the method used from 2012 and 2014 in two situations of great social impact in Brazil. The first situation refers to the restitution of property of the Telemar building in the city of Rio de Janeiro and the second one to the community of Pinheirinho, in São José dos Campos, in the State of São Paulo.

Keywords: collective eviction, judicial rulings, right to housing, communities, Brazil. 
Vol 35, Nº 51, (1-10), EISSN: 2215-2997, julio-diciembre, 2015

URL: www.revistas.una.ac.cr/abra

\section{Introducción}

El Poder Judicial brasileño, por medio del Supremo Tribunal Federal, ha decidido sobre varios temas de naturaleza política que el parlamento ha dejado de solucionar, como el aborto, la unión civil de personas del mismo sexo, el uso de células tronco embrionarias para fines científicos, el derecho afirmativo de cuotas raciales y sociales para ingresar a las universidades públicas, la prohibición del financiamiento privado de campañas electorales, sin justa causa, del cambio de partido en cargos de diputados, etc.

Por esto, y también en virtud de escándalos morales en que los diversos gobiernos y el parlamento se han envuelto, conforme aparece diariamente en los medios de comunicación, una corriente de científicos sociales y juristas brasileños han defendido el denominado "protagonismo judicial" frente a los demás poderes constituidos.

En este trabajo se hace una crítica al protagonismo judicial brasileño, particularmente el cuestionamiento a la posición adoptada por el Poder Judicial en casos de desalojo colectivo, cuando, por medio de decisiones expedidas de los jueces, miles de personas son echadas a la calle, de un día para otro, en las comunidades pobres, como se vio en las reintegraciones de pose del edificio de la Telemar, en la ciudad de Río de Janeiro, y en la Comunidad de Pinheirinho, en São José dos Campos, en el estado de São Paulo.

Así, por la densidad social del tema (desalojo colectivo), las decisiones sobre desocupación deberían ser tratadas como de naturaleza política, y no puramente técnico burocrática, que consideran exclusivamente la protección de la propiedad y quebrantan la dignidad humana.

\section{Un estado permanente de crueldad en Brasil}

De cierto modo, la sociedad brasileña se ha acostumbrado a la crueldad en su día a día, desde el periodo colonial hasta los días actuales, a medida que "la conquista portuguesa, la colonización, el imperio, la esclavitud y el genocidio de las naciones indígenas fueron ejercidos principalmente por la dominación coercitiva" (Almeida, 2012, p. 239). Y prosigue Almeida:

En Brasil, el Estado llegó de fuera para dentro. Fue una imposición por la fuerza de un estado colonizador representando a los grandes señores de tierra y a comerciantes, especialmente de esclavos. La violencia fue su gran signo. Así fue en el tiempo colonial, en el primero y en el segundo imperio, en la Republica vieja, en la brevísima experiencia democrática liberal restringida pos Revolución del 30, en la dictadura del Estado Nuevo, en el nuevo interregno liberal-democrático restringido hasta 1964 y en los 20 años de dictadura militar-burguesa (Almeida, 2012, p. 243). 
Por consiguiente, toda la formación política brasileña, desde el descubrimiento hasta por actualidad está pautada como consecuencia del poder, en que "la minoría gobierna siempre, en todos los tiempos, en todos los sistemas políticos" (Faoro, 2013, p. 828).

Sin embargo, la violencia derivada del proceso político de dominación se expande, en el país, hacia un estado permanente de crueldad, al tener en cuenta el grado de desigualdad y desequilibrio existente en las relaciones sociales, consecuente del "patrimonialismo, cuya legitimidad se apoya en el tradicionalismo -así es porque siempre fue-" (Faoro, 2013, p. 819), e impide los derechos elementales, previstos en textos legislativos, sean efectivos para la mayoría aplastadora del pueblo brasileño, así, "a la exclusión de los derechos económicos y sociales de gran parte de nuestra población" (Velloso, 2011, p. 23).

Según datos del Octavo Anuario de Seguridad Pública, del Foro Brasileño de Seguridad Pública, "la policía brasileña mató, en promedio, a seis personas por día entre el 2009 y el 2013. En cinco años, han sido 11.197 muertes, número superior al registrado por la policía americana a lo largo de 30 años (11.090)"1. Tal hecho es la constatación de lo que ya se sabe al respecto de los afamados "autos de resistencia", que "han sido blanco de crítica por la actuación violenta (de la policía) junto a determinados segmentos sociales, sobretodo, las clases populares" (Velloso, 2011, p. 37).

\section{Los jueces, como agentes intelectuales del Estado}

Para esto, es importante contar con agentes "intelectuales", que "son precisamente funcionarios" (Gramsci, 2014, p. 20) del Estado para acomodar las relaciones y evitar cualquier proceso de resistencia, por lo que el Poder Judicial es un importante agente en este escenario.

Así, se trata de un instrumento al servicio de las fuerzas hegemónicas, al contrario de lo que entienden los defensores del protagonismo judicial, que creen que, en el siglo XXI, este poder constituido podrá liderar a la sociedad excluida en la concretización de los derechos humanos, pues "los grandes problemas de hoy, entre ellos la propia gobernabilidad, están en manos del Judicial" (Lewandowski, 2014).

No obstante, como comentó Piovesan (2014, p. 17) “la población se siente distante del Poder Judicial; en América Latina, en promedio, entre un $70 \%$ y un $80 \%$ de la población tiene ese sentimiento. Al paso que el Judicial tiene la misma percepción de sentir distancia de la población".

Actualmente, el mencionado distanciamiento de la población no está explicado por Piovesan; sin embargo, suponemos que la masa poblacional no cree, de hecho, que el Poder Judicial pueda resolver los problemas del día a día, en la medida en que los jueces, a los ojos del pueblo, están

1 http://m.estadao.com.br/noticias/brasil,policia-brasileira-matou-seis-pessoas-por-dia-nos-ultimos-cinco-anos, 1590715,0.htm. Acceso en: $11 / 11 / 2014$. 
más cercanos a la represión (en virtud de la garantía individual de la seguridad patrimonial2) que a la solución, como se vio en las desocupaciones del edificio de la Telemar, en la ciudad de Río de Janeiro ${ }^{3}$, el 11 de abril de 2014, y de la comunidad de Pinheirinho, en São José dos Campos/SP4.

Además, el Poder Judicial, en función de su estructura, constituida de palacios de justicia, ceremoniales, lenguaje rebuscado etc., provoca una sensación de temor e inseguridad en una población avergonzada y amenazada cuando se enfrenta al aura de autoridad que emana de los jueces en sus togas negras; quienes se colocan arriba del pueblo, como se observa en cualquier audiencia de instrucción o sesión de juicio.

Piovesan defiende que está en curso la democratización de la Constitución, dado que:

El Supremo comenzó, incluso a realizar audiencias públicas para lidiar con esos casos tan relevantes (uso de células-tronco), tan difíciles. Estamos intentando ampliar la democratización de la Constitución, ampliar el círculo de intérpretes, conectarse con otros actores sociales, con otros saberes (Piovesan, 2014, p. 17).

Ahora, ¿cómo es posible creer en esa democratización si el pueblo aún no tiene consciencia de lo que es una Constitución? El hombre y la mujer, como individuos, todavía luchan por superar el egoísmo, cuando aún están "enfocados en sí mismos, en su interés particular, en su arbitrariedad privada y desagregado de la comunidad" (Marx, s.d., p. 33).

\section{El protagonismo judicial como retórica}

Con un pensamiento semejante al de Piovesan, Peluso (2011) afirmó que sería el tercer milenio "el siglo del Judicial" y que estaría ocurriendo una "revolución silenciosa del judicial brasileño". Esta visión, compartida por otros nombres, como Lewandowski (2014), parece bastante elitista y un tanto distante de la realidad, pues, al considerar que más del $70 \%$ de la población se encuentra distante del Poder Judicial, no es posible imaginar que la masa poblacional, excluida de todo y con dificultades para sobrevivir, esté participando directamente del supuesto proceso de democratización en curso en el Supremo Tribunal Federal, por medio de la judicialización de la política.

$2 \quad$ Marx (s.d., p. 32) resalta que “la seguridad es el concepto social supremo de la sociedad burguesa, el concepto de policía, según el cual toda la sociedad solamente existe para garantizar a cada uno de sus miembros la conservación de su persona, de sus derechos y de su propiedad". "Policiales y manifestantes se enfrentaron durante la reintegración de pose de un edificio desocupado de Telemar, grupo controlador de la Ol, en Río de Janeiro. El terreno, en el barrio Engenho Novo, fue ocupado por 5 mil habitantes hacía 11 días. 1600 policiales militares fueron destacados para hacer la reintegración de pose determinada por la Justicia" (http://epoca.globo.com/tempo/noticia/2014/04/reintegracao-de-posse-provoca-bconfrontob-no-rio-de-janeiro.html Acceso en: 18/08/2014)

4 "La Policía Militar cumple, desde las 6 h de este domingo (22/01/2012), un mandato de reintegración de pose en la comunidad de Pinheirinho, en São José dos Campos, al interior de São Paulo. De acuerdo con la policía, habitantes encendieron fuego en algunos puntos para dificultar la entrada de la policía, que utilizó municiones no letales para controlarlos, alrededor de las 8h20. (...) El área, que pertenece a la empresa Selecta, del grupo Naji Nahas, fue ocupada irregularmente en 2004 por una comunidad vinculada al MTST (Movimiento de los Trabajadores y Trabajadoras Sin-Techo). Por lo menos 1.600 familias, totalizando más de 5.500 personas, viven en el local." (http://noticias.r7.com/sao-paulo/ noticias/policia-cumpre-reintegracao-de-posse-no-pinheirinho-em-sao-jose-dos-campos-20120122.html Acceso en: 18/08/2014) 
Vol 35, Nº 51, (1-10), EISSN: 2215-2997, julio-diciembre, 2015

URL: www.revistas.una.ac.cr/abra DOI: http://dx.doi.org/10.15359/abra.35-51.5

Por consiguiente, no es el pueblo el que va al Supremo Tribunal Federal, son las minorías organizadas o sectores corporativos de la sociedad civil, las cuales tienen claros intereses particulares para ser atendidos.

En este punto, Santos (2007) tiene la expectativa de que los movimientos sociales puedan encontrar refugio para sus pretensiones en el Poder Judicial, pues:

Las clases populares que se habían habituado a que la única manera de hacer vengar sus intereses era estar al margen del marco jurídico demo liberal, comenzaron a ver que, organizadamente, podrían obtener algunos resultados por la apropiación, traducción, resignificación y utilización estratégica de esta legalidad". Y a partir de ahí, los movimientos comienzan a utilizar el derecho y los tribunales como un arma (Santos, 2007, p. 23).

Sin embargo, ocurre que algunas conquistas judiciales de los movimientos sociales son consecuencia del activismo de un grupo aislado de jueces; sin que esto represente la visión de la magistratura como un todo, como sucede en las discusiones judiciales promovidas contra las privatizaciones y las ventas de campos de petróleo de Brasil, cuando no fue promulgada ninguna decisión judicial expresiva y definitiva que fuera favorable a los movimientos sociales y en contra del poder económico hegemónico (Oliveira, 2005, pp. 582-583).

Por un lado, el facto de que las puertas del Poder Judicial estén, en tesis, abiertas para todos; no significa el acogimiento definitivo de las pretensiones del pueblo, que se contraponen a los intereses del capital, a modo de provocar un cambio o estremecimiento al régimen en curso. Se imagina que esto no es posible por la puerta de la Justicia, pues el Estado aún está vinculado a los intereses de la clase dominante ${ }^{5}$.

Por todos los rincones del mundo existen magistrados comprometidos con las transformaciones sociales y utópicas, como el juez español Baltasar Garzón (se aprovecha la oportunidad para rendirle un homenaje al juez, apartado de la magistratura por sus propios pares ${ }^{6}$ ); pero esos magistrados no representan el pensamiento vigente en sus instituciones, lo que hace evidente al imaginario popular que solamente los pobres están encarcelados en verdaderas mazmorras, como afirmó el ministro de Justicia de Brasil, José Eduardo Cardozo ${ }^{7}$, quien dijo que preferiría morir a estar preso en las penitenciarías del país.

5 Para Marx y Engels (2002, p. 74) “Estado no es otra cosa sino la forma de organización que los burgueses se dan a sí mismos por necesidad, para garantizar recíprocamente su propiedad y sus intereses (...)El Estado solo existe debido a la propiedad privada, tanto así que esa convicción pasó a la conciencia común".

6 "En España, el juez Baltasar Garzón se sienta esta mañana (17/01/2012) en el banco de los reos, juzgado por, alegadamente, haber ordenado escuchas ilegales en un caso de corrupción. Corre el riesgo de ser expulsado de la magistratura española (lo que de hecho se realizó). Baltasar Garzón se hizo conocido por haber acusado a Augusto Pinochet de genocidio y por haber dado inicio a un proceso relacionado con atrocidades cometidas durante la Guerra Civil de España." (http://www.rtp.pt/noticias/index.php?article=518809\&t$\underline{m}=7 \&$ layout $=122 \&$ visual $=61$ Acceso en: 13/08/2914)

7 "El ministro de Justicia, José Eduardo Cardozo, dijo este martes (13/11/2012) que preferiría morir a estar preso en las penitenciarías brasileñas, en caso de que fuera condenado por algún crimen. La afirmación fue realizada en una charla a empresarios en São Paulo, en la que Cardozo respondió una pregunta sobre si estaba de acuerdo con la pena de muerte. Cardozo dijo estar en contra a la pena capital y afirmo que las cárceles del país tienen condiciones "medievales". Él citó problemas que aún persisten como la violencia entre reos que acaba causando la muerte." (http://extra.globo.com/noticias/brasil/ministro-diz-que-prefere-morrer-passar-anos-em-cadeias-brasileñas-6718788.html\#ixzz3AJdg3Buu Acceso en: 13/08/2014). 
El Ministro de Justicia manifestó una verdad incontestable, conocida por cualquier hombre o mujer común, pues es el aparato estatal, a pedido del Ministerio Público y por decisión del Poder Judicial, que condena y mantiene a las personas en presidios que no presentan condiciones para la permanencia humana y, menos aún, para una supuesta recuperación o resocialización ${ }^{8}$.

Por lo tanto, no es creíble que las personas tengan fe en que el Poder Judicial esté ejecutando una "revolución democrática de la justicia" (Santos, 2007, p. 24). Tampoco será por la conciliación o mediación de conflictos de trabajo y los resultantes de relaciones de consumo, provocados por la ineficiencia estructural del capital, que el Poder Judicial podrá hacer la soñada "revolución".

En igual situación, la garantía de la seguridad de los contratos, de los marcos regulatorios y de las elevadas inversiones para digitalizar y convertir los procesos en formato electrónico no serán suficientes para transformar al judicial brasileño en una institución política cercana al pueblo, dado que:

En la apertura del Consejo de Derechos Humanos de la ONU, septiembre de 2006, el relator especial de la entidad que combate al racismo (el senegalés Doudou Diène) denunció que partes del Estado, del Judicial y de la sociedad civil brasileña resisten a medidas de combate al racismo.

Según el relator de la ONU, las comunidades más pobres del país son las mismas que fueron históricamente discriminadas - o sea, los negros y los indios. El texto identifica el racismo como una consecuencia del periodo de la esclavitud y apunta que el gobierno intenta enfrentar esa herencia. Según el relator, 'viajar por Brasil es como moverse entre dos planetas: uno es el de las calles, con colores vivos y razas mezcladas, y el otro es el de los corredores blancos de los poderes político, social, económico y de la prensa'. Él indica que será necesario un cambio intelectual y cultural para combatir la discriminación, siendo 'la democracia racial la máscara de la ideología de la élite brasileña para no decir que hay racismo', e incluso llama la atención para expresar el hecho de que el Judicial es muy conservador y con prejuicios raciales (Folena e Tavares, 2007, p. 42).

\section{Los desalojos colectivos como acto de crueldad}

Por consiguiente bajo la perspectiva, de que el Poder Judicial, aun siendo elevado a la condición de "protagonista" político, parece no tener la percepción de la crueldad y de la banalización de algunas de sus propias decisiones, que con respecto a la mantención del orden patrimonial desalojan de una vez, a más de cinco mil personas de los inmuebles donde residían, como se vio en las reintegraciones de pose del edificio de la Telemar, en la ciudad de Río de Janeiro, y en la comunidad de Pinheirinho, en São José dos Campos, en el estado de São Paulo, como se relató anteriormente.

$8 \quad$ El régimen carcelero también será examinado de forma más profunda, cuando analicemos la audiencia pública realizada por el Supremo Tribunal Federal sobre ese tema. 
A continuación, se presentan tres figuras ${ }^{9}$ relacionadas con el cumplimiento de una orden judicial de reintegración de pose, ocurrida el día 29 de mayo de 2014, que "retiró a aproximadamente 500 familias que invadieron un terreno de la Compañía de Desarrollo Habitacional y Urbano (CDHU) en la región de Guarapiranga, zona sur de São Paulo".

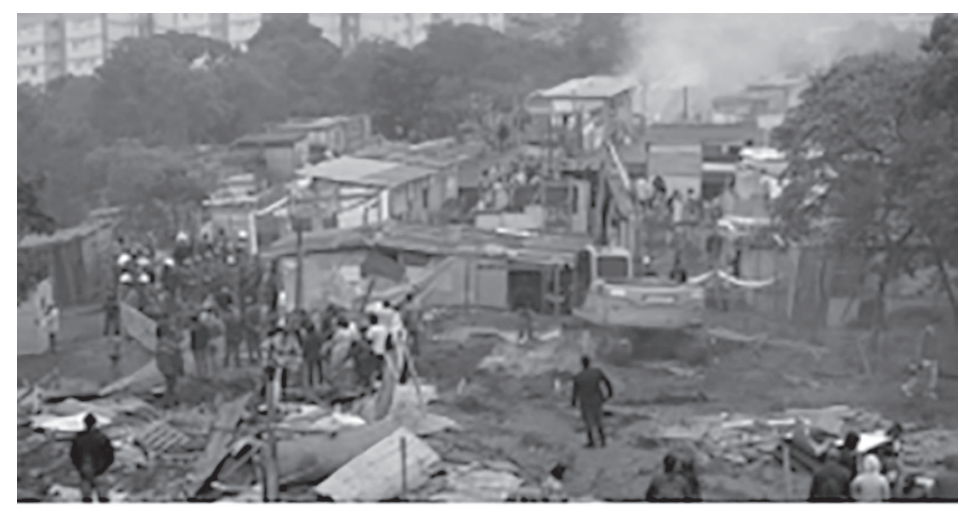

Figura 1. Desocupación Judicial el día 29 de mayo 2009, Compañía de Desarrollo de Vivienda y Urbanismo en la región de Guarapiranga en el lado sur de São Paulo. Fuente: http://noticias.band. uol.com.br/cidades/noticia/100000686106/sp-pm-retira-500-familias-de-terreno-invadido.html. Acceso en: 17 septiembre 2014.

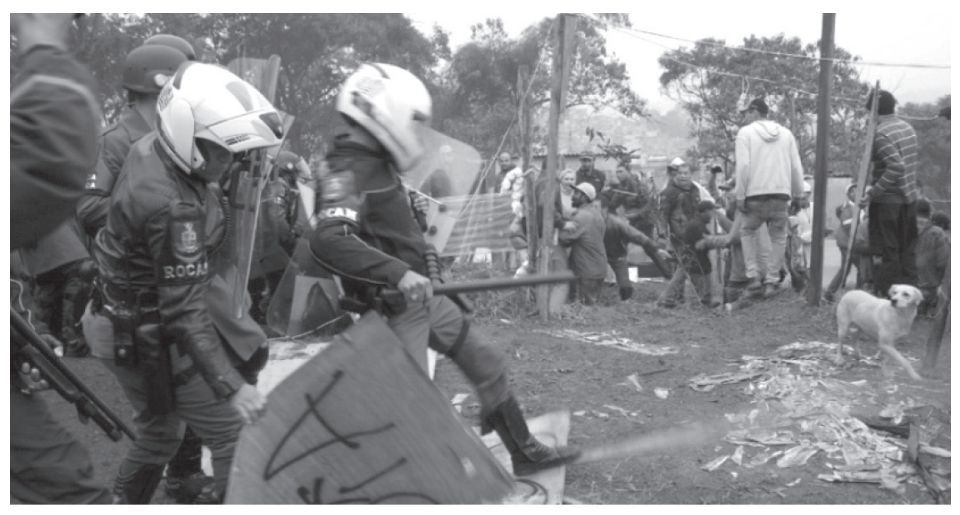

Figura 2. Desocupación Judicial el día 29 de mayo 2009, Compañía de Desarrollo de Vivienda y Urbanismo en la región de Guarapiranga en el lado sur de São Paulo. Fuente: http://noticias.band. uol.com.br/cidades/noticia/100000686106/sp-pm-retira-500-familias-de-terreno-invadido.html. Acceso en: 17 septiembre 2014.

Fotografía obtenidas en http://noticias.uol.com.br/album/2014/05/29/reintegracao-de-posse-em-sao-paulo.htm. Acceso en: 17 septiembre 2014. 


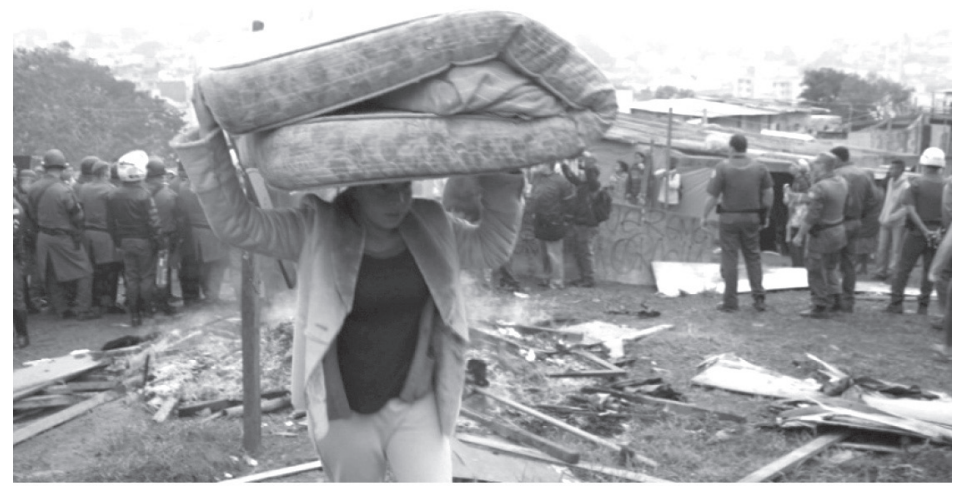

Figura 3. Desocupación Judicial el día 29 de mayo 2009, Compañía de Desarrollo de Vivienda y Urbanismo en la región de Guarapiranga en el lado sur de São Paulo. Fuente: http://noticias.band. uol.com.br/cidades/noticia/100000686106/sp-pm-retira-500-familias-de-terreno-invadido.html. Acceso en: 17 septiembre 2014.

En este orden de ideas, se resalta que existe una diferencia establecida entre la violencia y la crueldad. La violencia se impone como una necesidad política frente a acontecimientos fortuitos, en que no se espera su empleo, a pesar de imaginar que pueda suceder, por parte de las autoridades constituidas.

La crueldad, a priori, es consecuencia de acciones humanas, aceptadas por la moral, que se va transformando en actos comunes e incluso incuestionables, que son producto de los problemas sociales. Montaigne (1972, p. 207) da un ejemplo de esto, sobre la antigua Roma:"cuando se acostumbraron en Roma a los espectáculos de matanzas de animales, pasaron a los hombres y a los gladiadores".

La crueldad se vuelve banal al punto de agradar a la masa de la población y volverse un espectáculo público, promovido y organizado por el Estado, como lo describe Saramago (1989) al respecto de los autos-de-fe, en Lisboa, al inicio del siglo XVIII:

No obstante, hoy es día de alegría general, quizá la palabra sea impropia, porque el gusto viene de más hondo, tal vez del alma, mirar esa ciudad saliendo de sus casas dispersa calles y plazas, bajando de las lomas, juntándose en el Rossío para ver cómo justician a judíos y a cristianos-nuevos, a herejes y hechiceros (...). Y habiendo pasado ya casi dos años sin que se quemara gente en Lisboa, está el Rossío lleno de gente, dos veces festiva por ser domingo y por haber auto-de-fe, que nunca se llegará a saber de qué gustan más los moradores, si de esto, si de las corridas de toros, incluso cuando sólo éstas se usen. En las ventanas que dan a la plaza hay mujeres, vestidas y tocadas con primor, a la alemana por gracia de la reina (...). El-rey, con los infantes, sus hermanos y sus hermanas las infantas, 
comerá en la Inquisición, finalizado ya el auto de fe, y aliviado de su incomodo honrará la mesa del inquisidor-general (...) (Samarango, 1989, pp. 50-51).

La crueldad tiene como marca indeleble su aceptación moral en la sociedad, sin cuestionamientos, como se observa en muchas decisiones del poder estatal. Se cree que los dirigentes estatales aún hoy, como ocurría en la Roma Antigua y en los actos de la inquisición del régimen-feudal absolutista, no se dan cuenta de las consecuencias de sus decisiones, aceptadas con normalidad por la sociedad, excepto a las personas directamente alcanzadas, que se revelan naturalmente e intentan escapar de sus consecuencias.

\section{Conclusiones}

Por lo tanto, un poder que echa a la calle a miles de personas, como se vio en las reintegraciones de pose del edificio de la Telemar, en la ciudad de Río de Janeiro, y en la comunidad de Pinheirinho, en São José dos Campos, en el estado de São Paulo, no puede ser considerado un protagonista político, como lo defiende la corriente de científicos sociales y juristas brasileños, mencionada anteriormente.

Por más que el Poder Judicial haya decidido causas de gran repercusión social (como lo hizo el Supremo Tribunal Federal en los casos de autorización del aborto, reconocimiento de la unión civil de personas del mismo sexo y prohibición del financiamiento privado de las campañas electorales), eso no lo posiciona sobre los demás poderes constituidos.

El Poder Judicial hace parte del aparato represivo del Estado, por lo cual sus decisiones de naturaleza burocrática y técnica no pueden sobreponerse a las decisiones políticas, como ocurre en los desalojos colectivos; que por la constancia de los casos y por incluir a tanta gente (niños, ancianos, mujeres) acaban caracterizándose como actos de crueldad.

Tales decisiones deben ser de naturaleza política y exigen una mayor discusión en el seno de la sociedad, con el fin de evitar abusos económicos y también que los intereses privados puedan estar por encima de los derechos sociales.

Así, no es posible creer en un protagonismo judicial en el siglo XXI, una vez que los desalojos colectivos son realizados por fuerzas retrógradas que, incluso en la era de la contemporaneidad, intentan elevar las estructuras del viejo Estado Feudal a "protagonistas" de la Historia, por medio de imaginadas "revoluciones", que creen ser capaces de solucionar todos los problemas. Por eso, no es posible creer que el Poder Judicial pueda absorber esta gran responsabilidad, que depositan sobre sus hombros. 


\section{Referencias bibliográficas}

Almeida, J. (2012). Hegemonia e bloco histórico no Brasil pós Lula da Silva. In CLOUX, R.F. e FERREIRA, E.B. (Orgs.). Hegemonia \& resistência no Brasil. Salvador: Kawo-Kabiyesile.

Faoro, R. (2013). Os donos do poder - formação do patronato político brasileiro. São Paulo: Editora Globo. doi: $10.2307 / 2514002$.

Folena, J.R. \& Tavares, V. (2007). As empresas públicas e o desenvolvimento sustentável. Um Brasil dos brasileiros. Rio de Janeiro: ARC Editor.

Gramsci, A. (2014). Cadernos do cárcere (v. 2). Rio de Janeiro: Civilização Brasileira.

Lewandowski, R. (2014). Judiciário tem papel de protagonismo no funcionamento do Estado. Notícias do Supremo Tribunal Federal, 21 nov. 2014. Disponível em: http://www.stf.jus.br/por$\mathrm{tal} / \mathrm{cms} /$ verNoticiaDetalhe.asp?idConteudo=280306\&tip=UN. Acesso em: 24 nov. 2014.

Marx, K. (S.d.). A questão judaica. Rio de Janeiro: Achiamé.

Marx, K. e Engels, F. (2002). A idelogia alemã. São Paulo: Martins Fontes.

Montaigne, M. (1972). Ensaios. São Paulo: Editora Abril. Os Pensadores.

Oliveira, V. (2005). Judiciário e privatizações no Brasil: existe uma judicialização da política? Rio de Janeiro: Revista de Ciências Sociais, v. 48, n. 3. doi: 10.1590/S0011-52582005000300004.

Peluso, C. (2011). Notícias do STF, de 01 fev. 2011. Disponível em: <http://www.stf.jus.br/portal/ processo/verProcessoAndamento.asp?incidente=4397298www.stf.jus.br/portal/cms/ verNoticiaDetalhe.asp?idConteudo=170645. Acesso em: 27 out. 2013.

Piovesan, F. (2014) Por um judiciário democrático. Entrevista à Revista Caros Amigos. Ano XVII, n. 69.

Saramago, J. (1989). Memorial do convento. Rio de Janeiro: Bertrand.

Santos. B.S. (2007). Para uma revolução democrática da justiça. São Paulo: Editora Cortez.

Velloso, S.C.S. (2011). Autos de resistência, algumas considerações sobre tráfico de drogas e letalidade policial nas favelas do Rio de Janeiro. Rio de Janeiro: Multifoco. 